Supplement of Hydrol. Earth Syst. Sci., 22, 1629-1648, 2018

https://doi.org/10.5194/hess-22-1629-2018-supplement

(c) Author(s) 2018. This work is distributed under

the Creative Commons Attribution 4.0 License.

(c) (1)

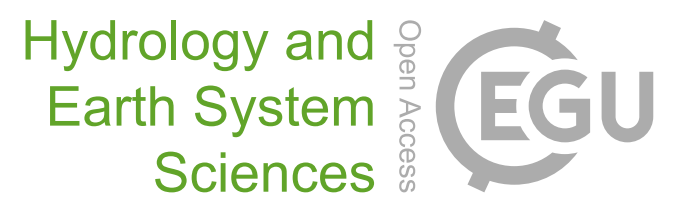

Supplement of

\title{
Using hydraulic head, chloride and electrical conductivity data to dis- tinguish between mountain-front and mountain-block recharge to basin aquifers
}

Etienne Bresciani et al.

Correspondence to: Etienne Bresciani (etienne.bresciani@flinders.edu.au)

The copyright of individual parts of the supplement might differ from the CC BY 4.0 License. 


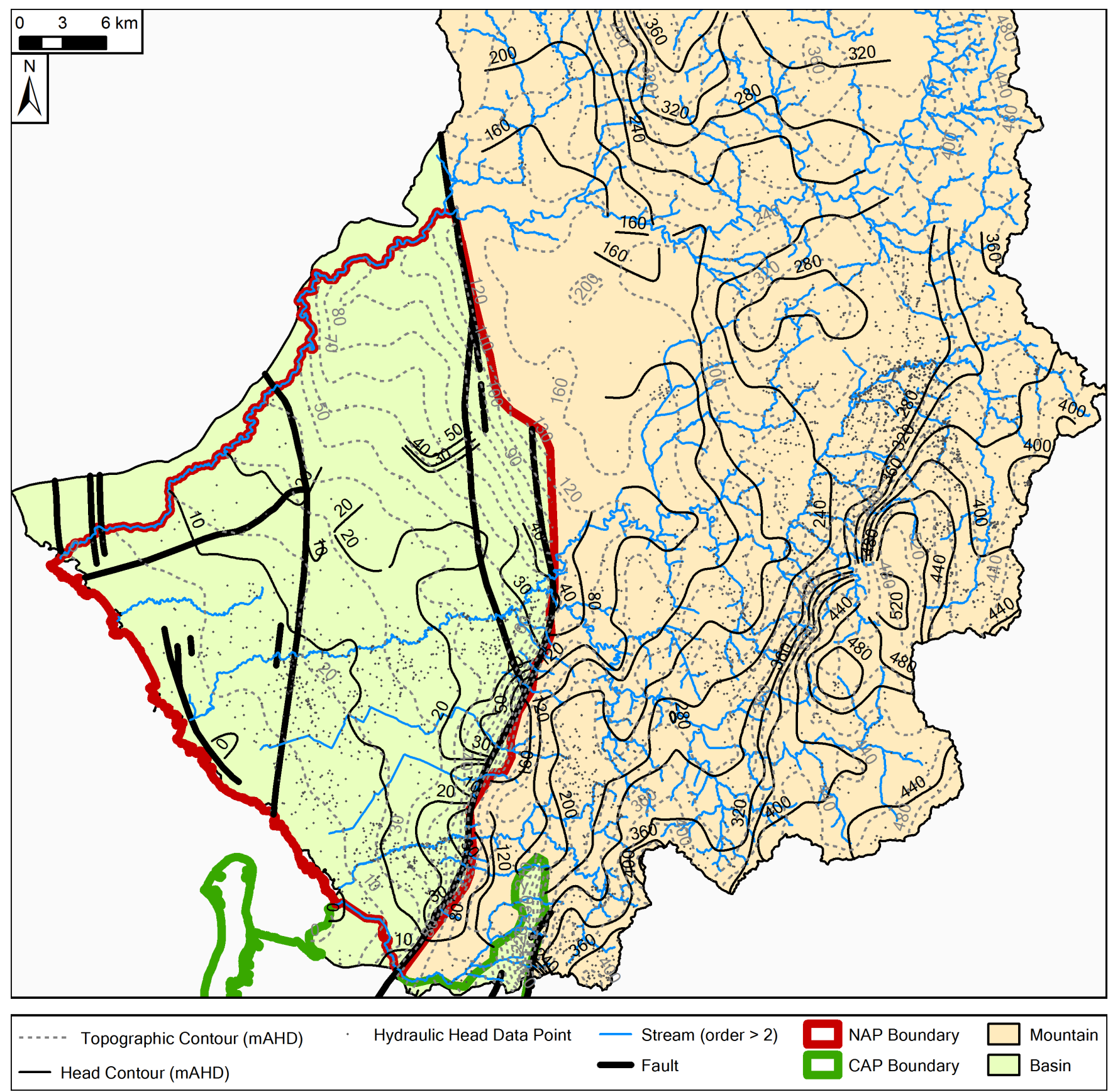

Figure S1. Head and topographic contours in the NAP catchment. On the basin side, the Quaternary aquifers are shown. On the mountain side, the Mount Lofty Ranges aquifers are shown. The contour interval is $10 \mathrm{~m}$ in the basin and $40 \mathrm{~m}$ in the mountain (both for head and topography). There is no data further north. 


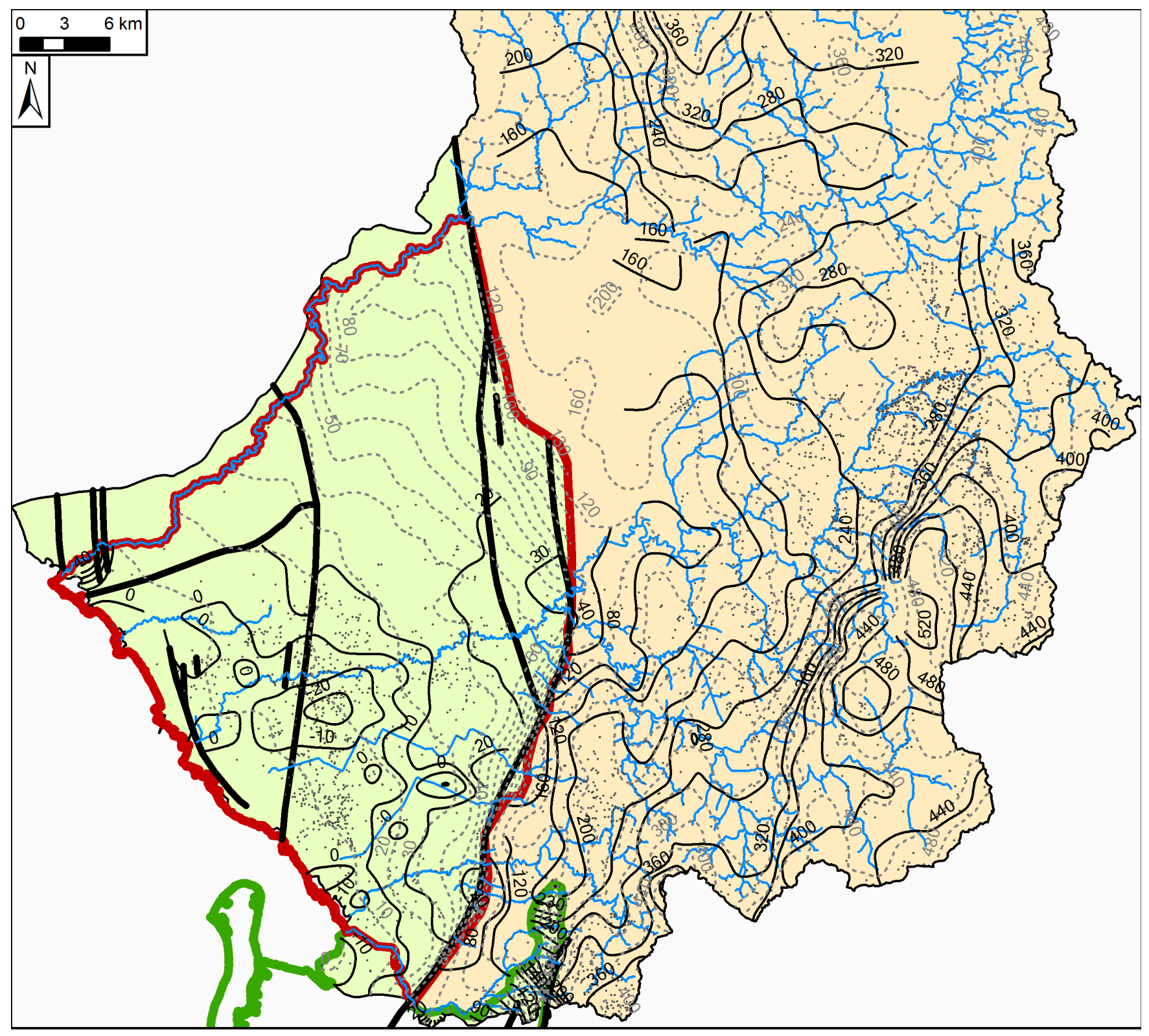

\begin{tabular}{|llll|}
\hline$=\ldots$ Topographic Contour (mAHD) & Hydraulic Head Data Point & Stream (order $>2)$ & NAP Boundary \\
Head Contour (mAHD) & Fault & Mountain \\
\hline CAP Boundary
\end{tabular}

Figure S2. Head and topographic contours in the NAP catchment. On the basin side, the Tertiary aquifers are shown. On the mountain side, the Mount Lofty Ranges aquifers are shown. The contour interval is $\mathbf{1 0} \mathbf{~ m}$ in the basin and $40 \mathrm{~m}$ in the mountain (both for head and topography). There is no data further north. 


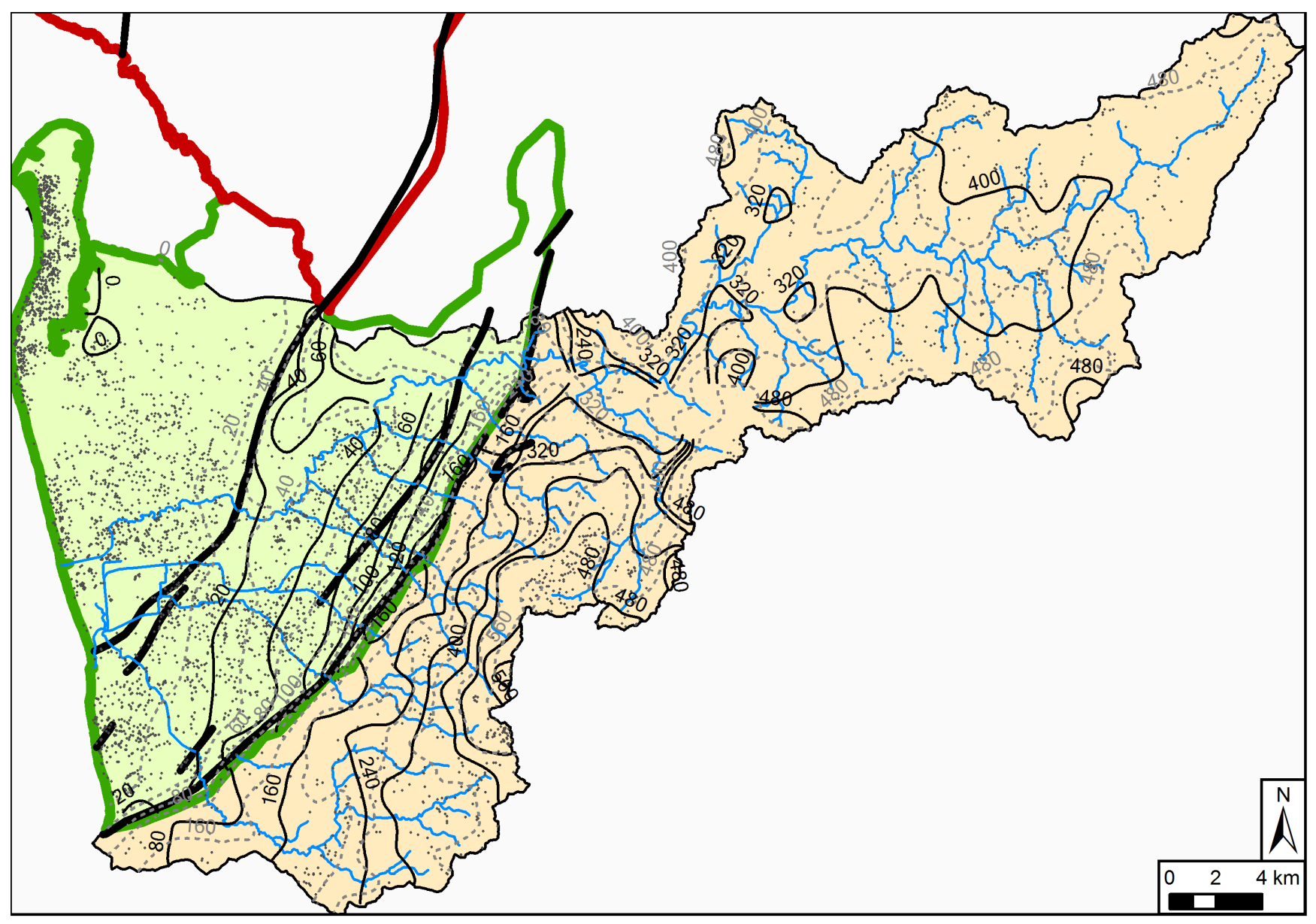

\begin{tabular}{|llll|}
\hline- - - Topographic Contour (mAHD) & Hydraulic Head Data Point & Stream (order $>2)$ & NAP Boundary \\
\hline Head Contour (mAHD) & Fault & CAP Boundary \\
\hline Bain
\end{tabular}

Figure S3. Head and topographic contours in the CAP catchment. On the basin side, the Quaternary aquifers are shown. On the mountain side, the Mount Lofty Ranges aquifers are shown. The contour interval is $20 \mathrm{~m}$ in the basin and $80 \mathrm{~m}$ in the mountain (both for head and topography). 


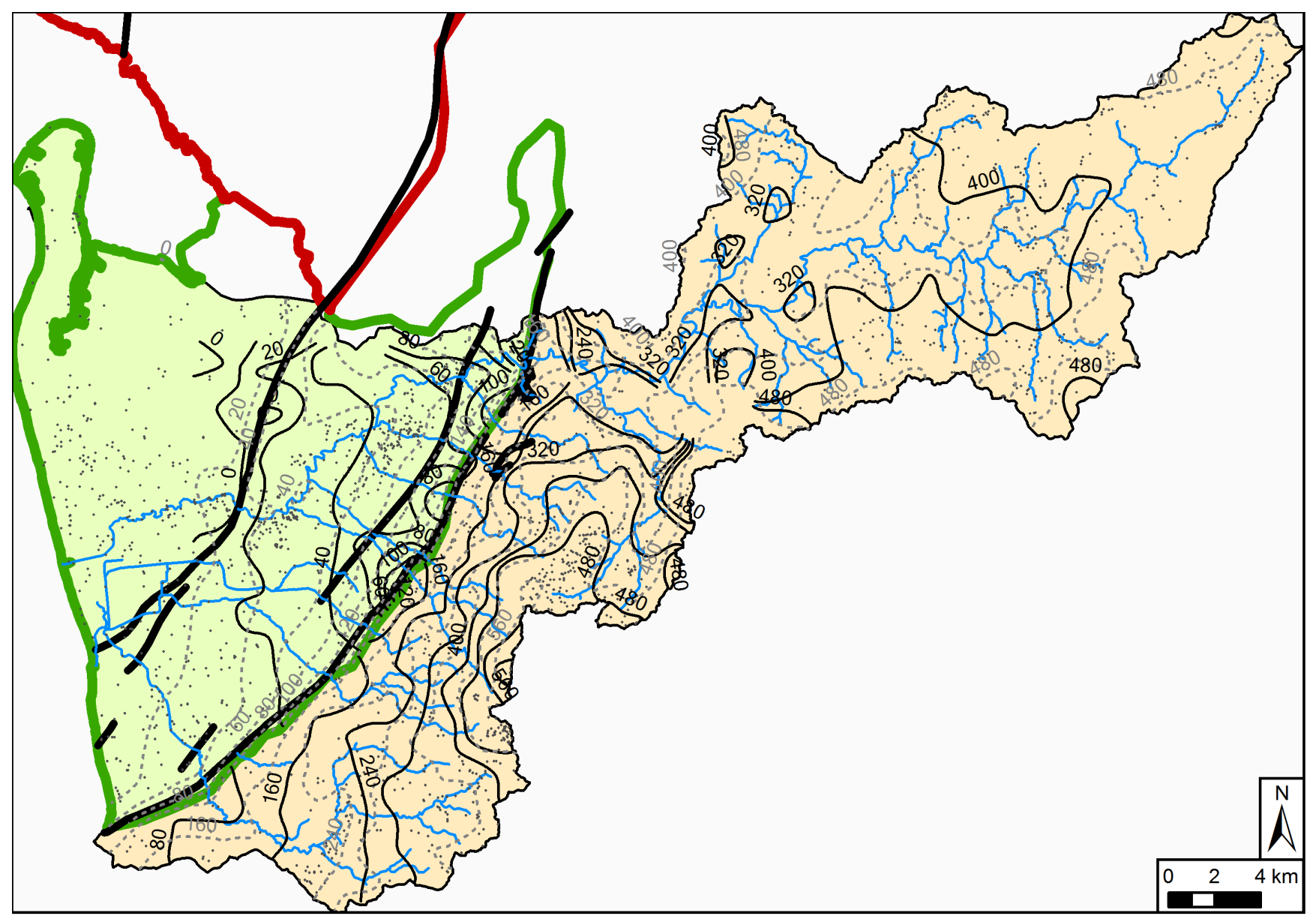

\begin{tabular}{|llll|}
\hline- - - Topographic Contour (mAHD) & Hydraulic Head Data Point & Stream (order > 2) & NAP Boundary \\
- Head Contour (mAHD) & Fault & CAP Boundary \\
\hline Basin
\end{tabular}

Figure S4. Head and topographic contours in the CAP catchment. On the basin side, the Tertiary aquifers are shown. On the mountain side, the Mount Lofty Ranges aquifers are shown. The contour interval is $20 \mathrm{~m}$ in the basin and $80 \mathrm{~m}$ in the mountain (both for head and topography). 


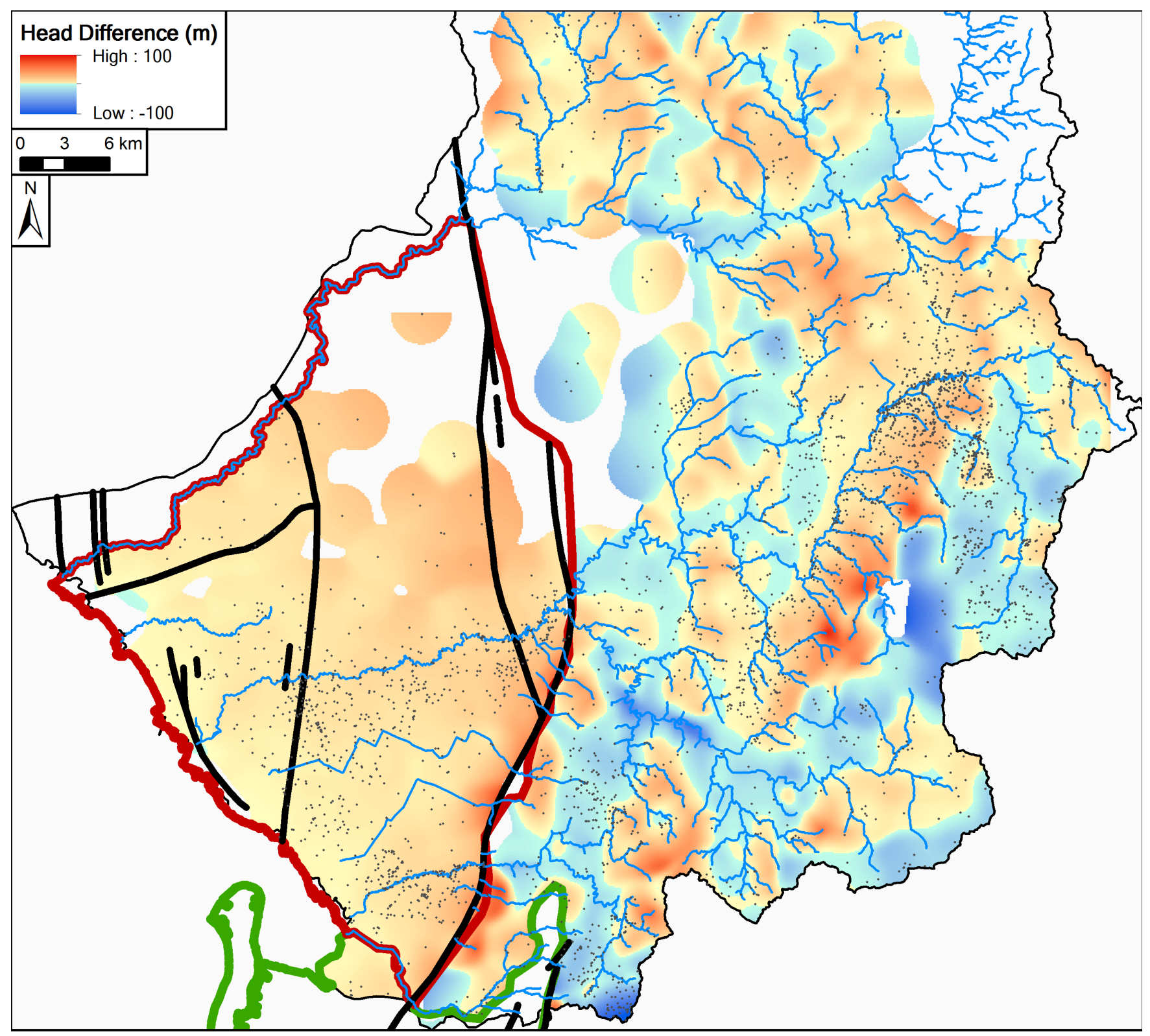

$$
\begin{array}{lll}
\text { Hydraulic Head Data Point } & \text { Stream (order }>2) & \text { NAP Boundary } \\
& \text { Fault } & \text { CAP Boundary }
\end{array}
$$

Figure S5. Head differences in the NAP catchment. On the basin side, the nearest river head (approximated by topography) minus the head in the Quaternary aquifers is shown. On the mountain side, the nearest river head (approximated by topography) minus the head in the Mount Lofty Ranges aquifers is shown. There is no data further north. 


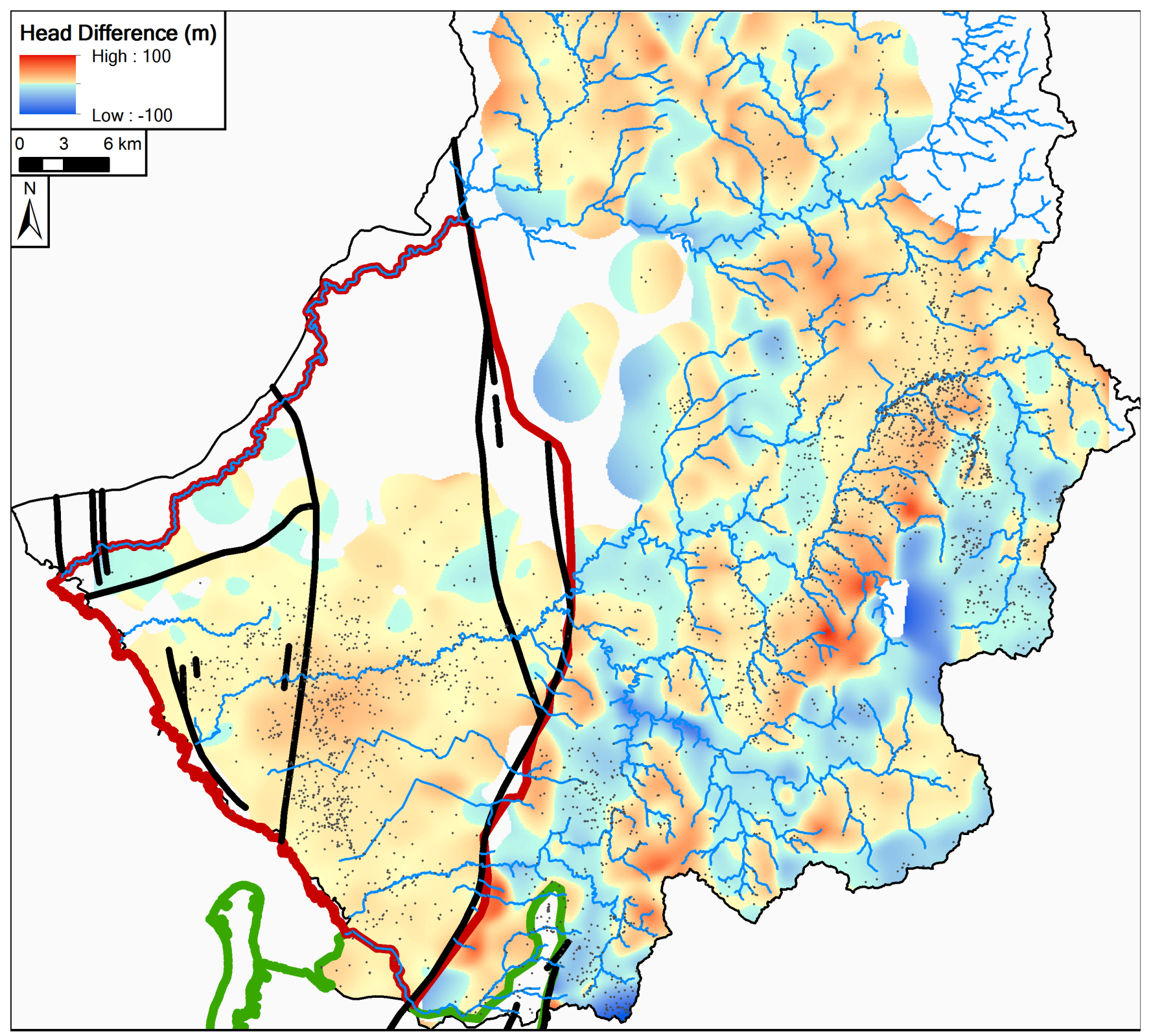

$$
\begin{array}{lll}
\text { Hydraulic Head Data Point } & \text { Stream (order }>2) & \text { NAP Boundary } \\
& \text { Fault } & \text { CAP Boundary }
\end{array}
$$

Figure S6. Head differences in the NAP catchment. On the basin side, the head in the Quaternary aquifers minus the head in the Tertiary aquifers is shown. On the mountain side, the nearest river head (approximated by topography) minus the head in the Mount Lofty Ranges aquifers is shown. There is no data further north. 


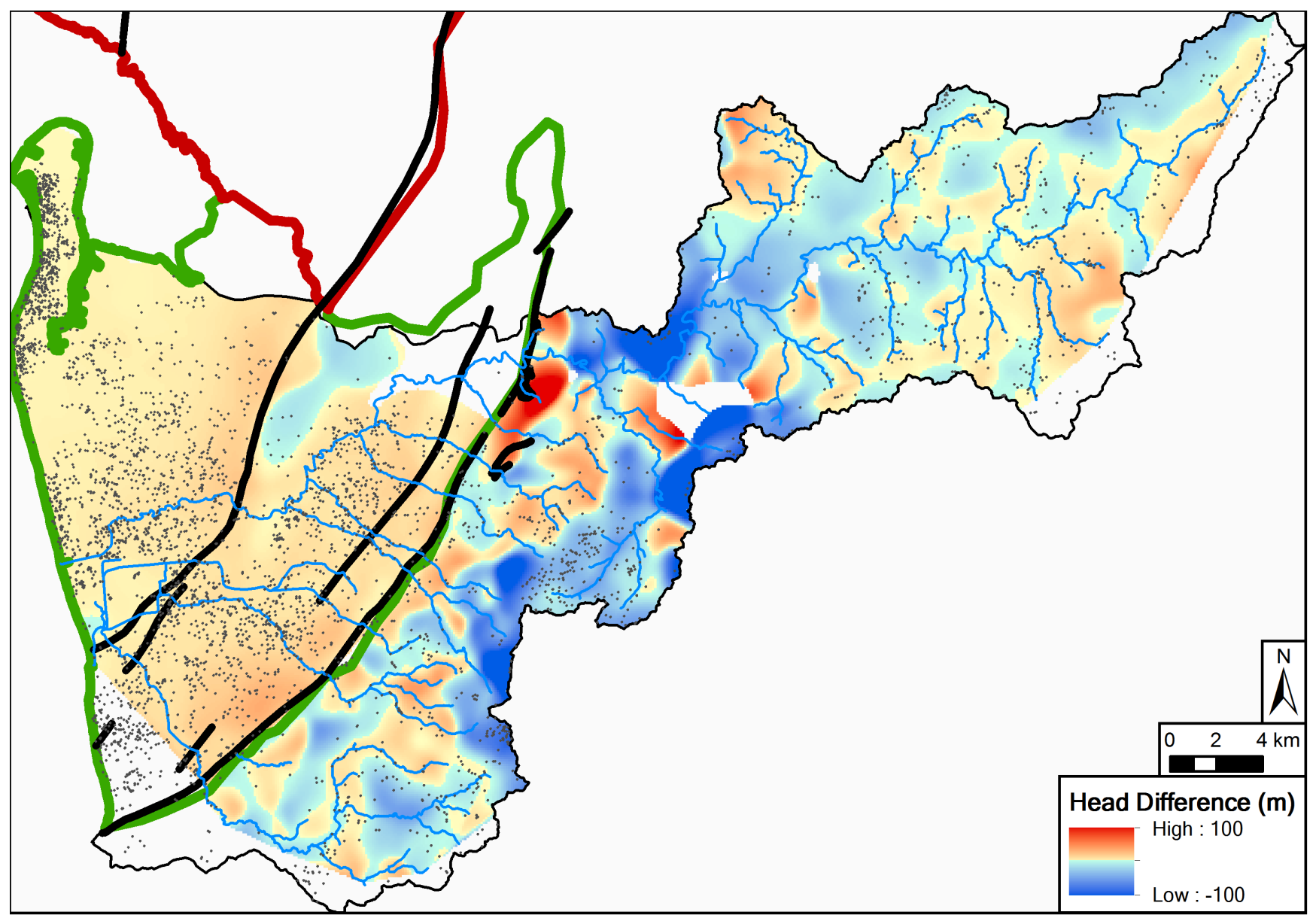

$$
\begin{array}{lll}
\text { Hydraulic Head Data Point } & \text { Stream (order }>2) & \text { NAP Boundary } \\
& \text { Fault } & \text { CAP Boundary }
\end{array}
$$

Figure S7. Head differences in the CAP catchment. On the basin side, the nearest river head (approximated by topography) minus the head in the Quaternary aquifers is shown. On the mountain side, the nearest river head (approximated by topography) minus the head in the Mount Lofty Ranges aquifers is shown. 


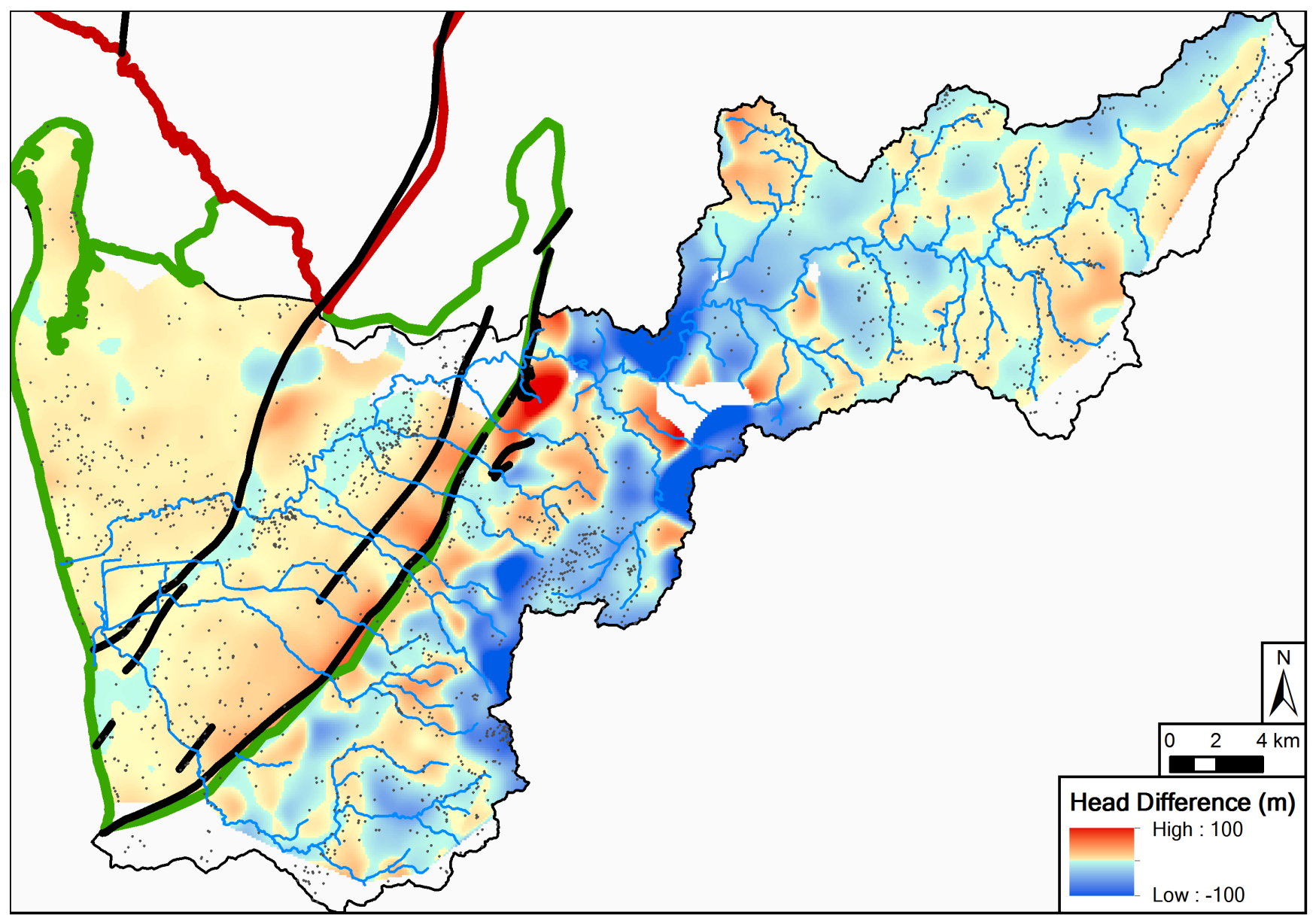

$$
\begin{array}{lll}
\text { Hydraulic Head Data Point } & \text { Stream (order }>2) & \text { NAP Boundary } \\
& \text { Fault } & \text { CAP Boundary }
\end{array}
$$

Figure S8. Head differences in the CAP catchment. On the basin side, the head in the Quaternary aquifers minus the head in the Tertiary aquifers is shown. On the mountain side, the nearest river head (approximated by topography) minus the head in the Mount Lofty Ranges aquifers is shown. 

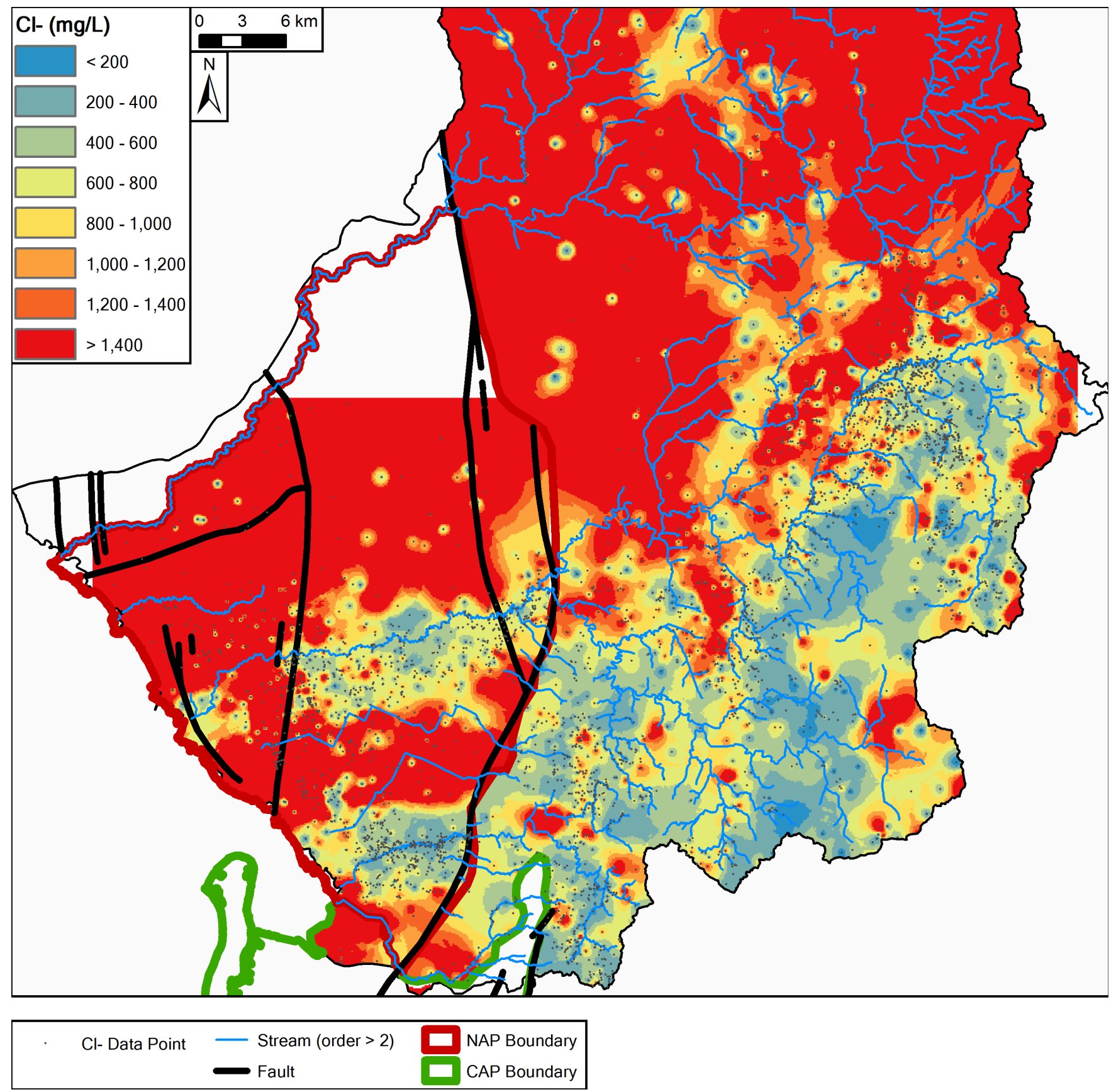

Figure S9. Chloride concentrations in the NAP catchment. On the basin side, the Quaternary aquifers are shown. On the mountain side, the Mount Lofty Ranges aquifers are shown. The same colour scheme is applied everywhere and is chosen favourable to the study of relatively low salinity zones. I.e., all $\mathrm{Cl}^{-}$concentrations larger than $1,400 \mathrm{mg} \mathrm{L}^{-1}$ are included in the same class (red colour), but in reality much higher values exist. There is no data further north. 

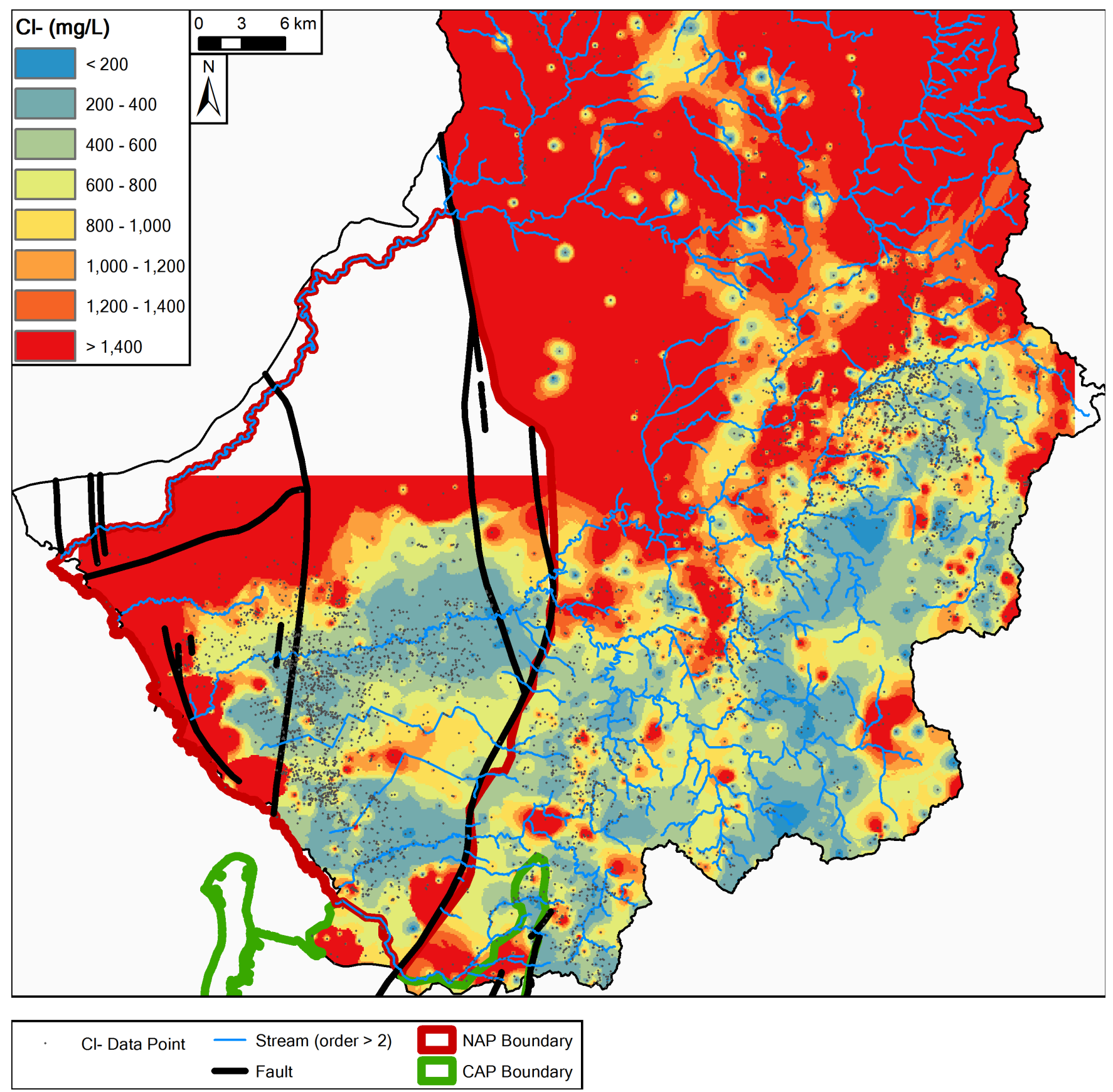

Figure S10. Chloride concentrations in the NAP catchment. On the basin side, the Tertiary aquifers are shown. On the mountain side, the Mount Lofty Ranges aquifers are shown. The same colour scheme is applied everywhere and is chosen favourable to the study of relatively low salinity zones. I.e., all $\mathrm{Cl}^{-}$concentrations larger than $1,400 \mathrm{mg} \mathrm{L}^{-1}$ are included in the same class (red colour), but in reality much higher values exist. There is no data further north. 


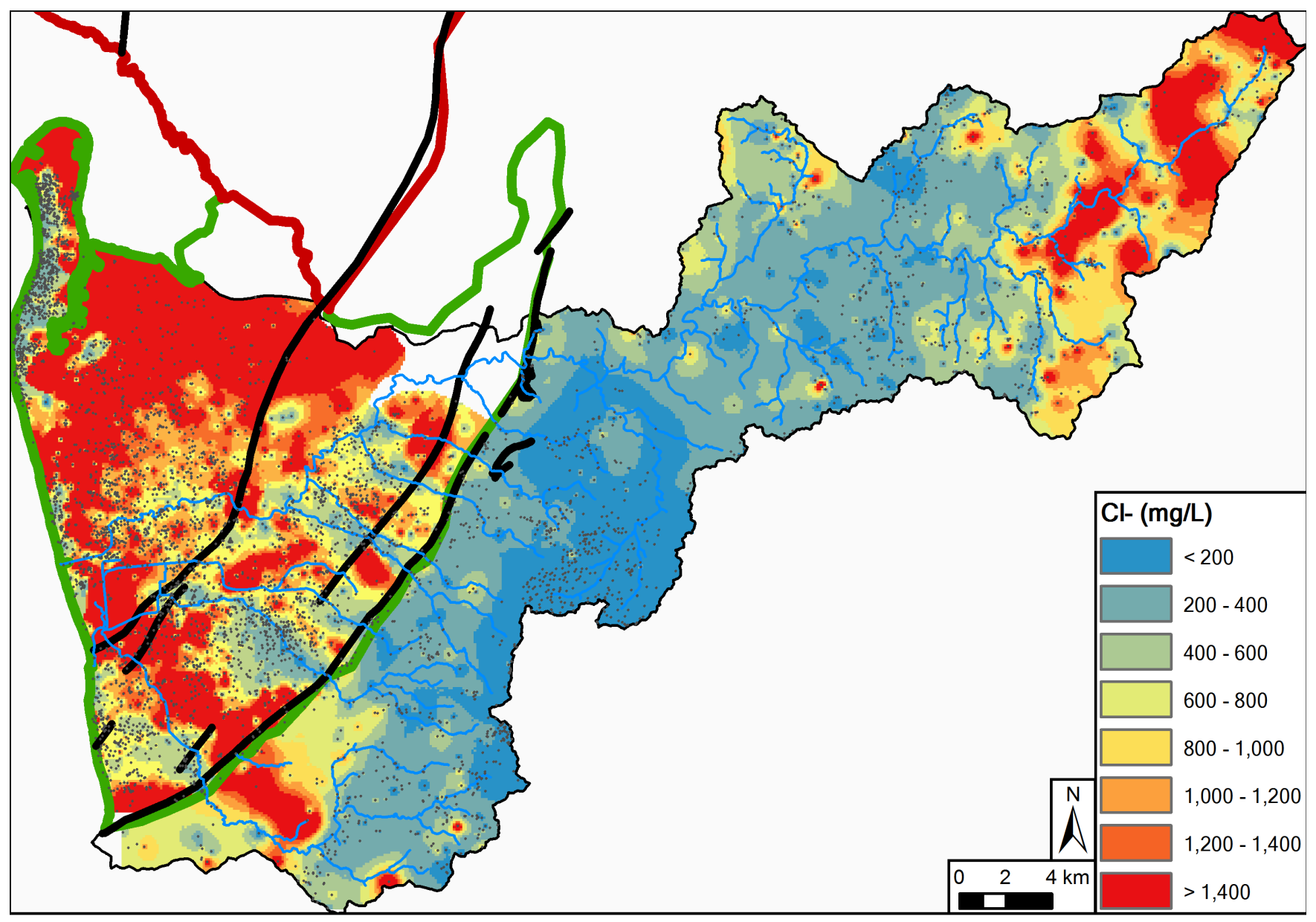

$$
\begin{array}{lll}
\text { Cl- Data Point } & \text { Stream (order }>2) & \text { NAP Boundary } \\
& \text { Fault } & \text { CAP Boundary }
\end{array}
$$

Figure S11. Chloride concentrations in the CAP catchment. On the basin side, the Quaternary aquifers are shown. On the mountain side, the Mount Lofty Ranges aquifers are shown. The same colour scheme is applied everywhere and is chosen favourable to the study of relatively low salinity zones. I.e., all $\mathrm{Cl}^{-}$concentrations larger than $1,400 \mathrm{mg} \mathrm{L}^{-1}$ are included in the same class (red colour), but in reality much higher values exist. 


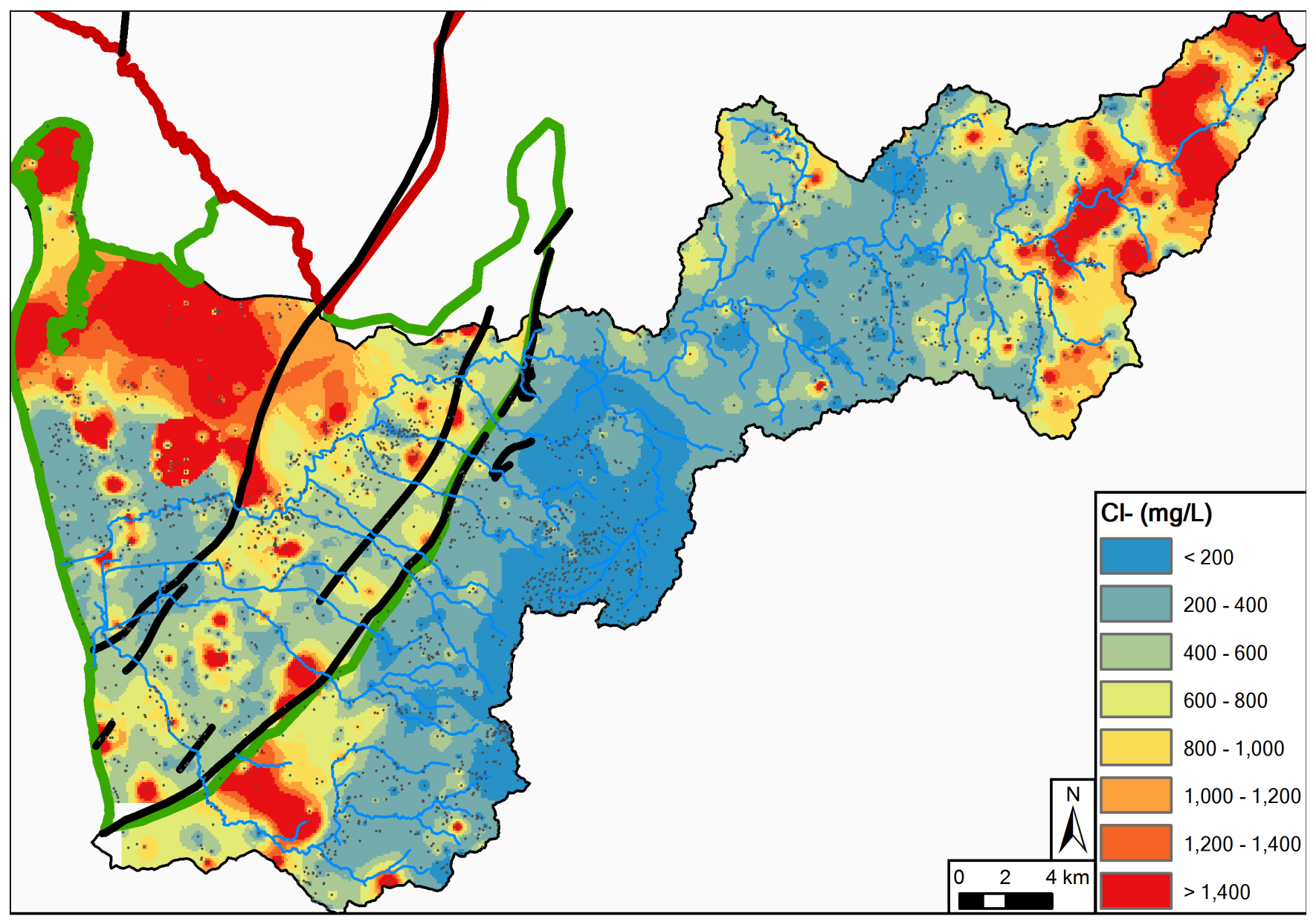

\begin{tabular}{|lll|}
\hline Cl- Data Point & Stream (order $>2)$ & NAP Boundary \\
& Fault & CAP Boundary \\
\hline
\end{tabular}

Figure S12. Chloride concentrations in the CAP catchment. On the basin side, the Tertiary aquifers are shown. On the mountain side, the Mount Lofty Ranges aquifers are shown. The same colour scheme is applied everywhere and is chosen favourable to the study of relatively low salinity zones. I.e., all $\mathrm{Cl}^{-}$concentrations larger than $1,400 \mathrm{mg} \mathrm{L}^{-1}$ are included in the same class (red colour), but in reality much higher values exist. 


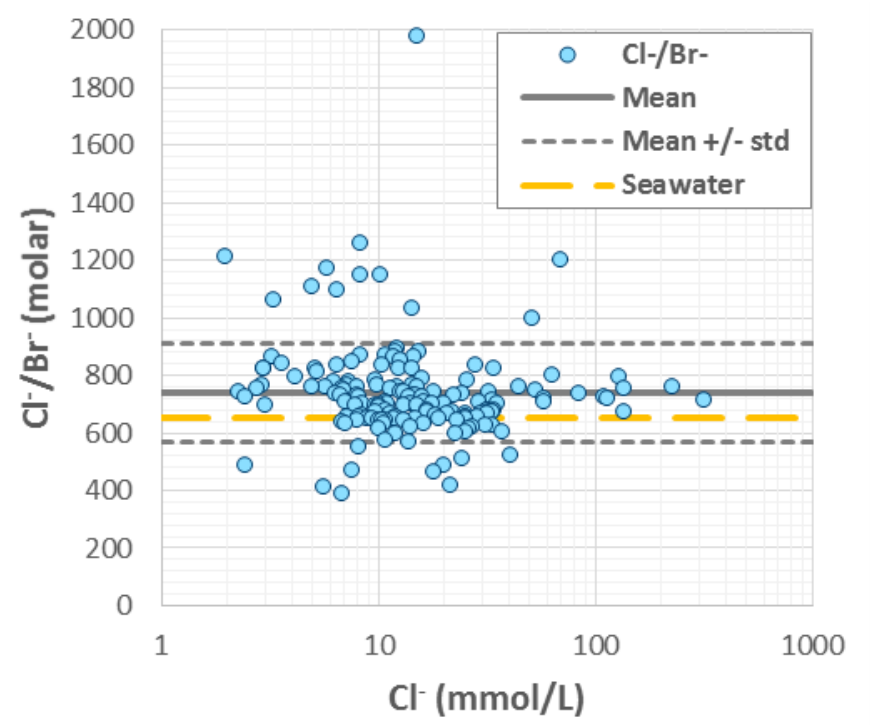

Figure $\mathrm{S} 13 . \mathrm{Cl}^{-} / \mathrm{Br}^{-}$ratio from 161 groundwater samples in the AP basin. The data were retrieved from the WaterConnect database, which contained both $\mathrm{Br}^{-}$and $\mathrm{Cl}^{-}$concentrations for 173 wells. The 12 highest $\mathrm{Cl}^{-} / \mathrm{Br}^{-}$ratio values were excluded in the present analysis because they appear as outsiders (maximum value: 33,619 (molar)). 